TITLE:

\title{
Estimation of the Type Locality of Hynobius naevius (Temminck and Schlegel, 1838), a Salamander from Japan (Amphibia: Caudata)
}

\section{$\operatorname{AUTHOR}(\mathrm{S})$ :}

Tominaga, Atsushi; Matsui, Masafumi

\section{CITATION:}

Tominaga, Atsushi ... [et al]. Estimation of the Type Locality of Hynobius naevius (Temminck and Schlegel, 1838), a Salamander from Japan (Amphibia: Caudata). Zoological Science 2007, 24(9): 940-944

\section{ISSUE DATE:}

2007-09

URL:

http://hdl.handle.net/2433/85319

\section{RIGHT:}

(c) 日本動物学会 / Zoological Society of Japan 


\title{
Estimation of the Type Locality of Hynobius naevius (Temminck and Schlegel, 1838), a Salamander from Japan (Amphibia: Caudata)
}

\author{
Atsushi Tominaga and Masafumi Matsui ${ }^{\star}$ \\ Graduate School of Human and Environmental Studies, Kyoto University, \\ Yoshida, Sakyo-ku, Kyoto 606-8501, Japan
}

\begin{abstract}
A small Japanese salamander, Hynobius naevius, long considered a single species, has recently proven to include two groups (Group $A=$ large type and Group B=small type) that are split at the species level. We compared the type series of $H$. naevius with specimens of the two groups to clarify which of them corresponds to true $H$. naevius, and to estimate the type locality of this species, which was not given in detail in its original description. Results of various morphological analyses altogether indicated that the type series belongs to Group A and that the population sample from Mt. Tara-dake, located on northwestern Kyushu, is most similar to the type series. Therefore, the type locality of the species is estimated to be in northwestern Kyushu. These results also indicate that Group B obviously represents a cryptic species whose scientific name remains to be determined.
\end{abstract}

Key words: cryptic species, discriminant analysis, Hynobiidae, lectotype, morphological variation

\section{INTRODUCTION}

Hynobius naevius (Temminck and Schlegel, 1838) is a lotic-breeding salamander widely distributed in western Japan. The species was originally described as Salamandra naevia without accurate indication of the type locality (Temminck and Schlegel, 1838; Dunn, 1923). Although high morphological variation has been reported for this species (Oyama, 1940; Sato, 1943), intensive taxonomic studies have scarcely been done. Oyama $(1940,1947)$ studied morphological variation in this species and designated the population from Aso, Kumamoto Prefecture, central Kyushu, as a distinct subspecies, $H$. $n$. yatsui. However, the validity of this nominate subspecies has never been evaluated. Thus, $H$. naevius has usually been regarded as a monotypic species (Matsui and Misawa, 1996), although $H$. kimurae was once regarded as a subspecies of this species (Nakamura and Uéno, 1963; Kuramoto, 1979: but see Matsui, 1981).

Recent morphological, genetic, and ecological surveys by Tominaga et al. (2003, 2005a,b, 2006) and Sakamoto et al. (2005), revealed that $H$. naevius is composed of two distinct groups, one from Chugoku and northern Kyushu (type A of Tominaga et al., 2003; Group A=large type of Tominaga et al., 2005a,b; Clades 1 and 2 of Tominaga et al., 2006; Group I of Sakamoto et al., 2005), and the other from western Chubu, Kinki, Shikoku, and Kyushu (type B of Tominaga et al., 2003; Group B=small type of Tominaga et al., 2005a,b; Clades 3 and 4 of Tominaga et al., 2006; Group II of Sakamoto et al., 2005). These authors also reported that these two groups occur sympatrically in northern Kyushu and are reproductively isolated

\footnotetext{
* Corresponding author. Phone: +81-75-753-6846; Fax : +81-75-753-2891; E-mail: fumi@ zoo.zool.kyoto-u.ac.jp
}

from each other, indicating that the two groups of $H$. naevius should be recognized as separate species.

In this study, we compared the type series of $H$. naevius stored in European museums with specimens of the two groups from various localities representing whole of their distributional ranges. Our purposes are to clarify which of the two groups represent $H$. naevius and to estimate the type locality of this species.

\section{MATERIALS AND METHODS}

Syntypes of $S$. naevia $(=H$. naevius) were distributed to several European museums (Sato, 1943), and a lectotype was designated by Hoogmoed (1978) among specimens in the Rijksmuseum van Natuurlijke Historie, Leiden (RMNH). We examined the lectotype and some paralectotypes stored in RMNH and The Natural History Museum, London (BM) (Table 1). Because internal organs, including gonads, had been removed in the type specimens, their sex and maturity status are unknown. Of a total of 14 specimens accessed (Table 1), seven individuals (including the lectotype, RMNH 2306A) were selected, because these specimens were considered to be adults from their body size [SVL (snout-vent length) $>72 \mathrm{~mm}$ ] and a complete data set was available for each of them. Paralectotypes in RMNH is collectively numbered 2306 , and only three of them were tagged (B-D). For convenience, we sequentially numbered the remaining paralectotypes examined (Table 1). We treated these type specimens as one sample under an a priori assumption that all are from the same local population. For comparison with the type series, we used a total of 658 individuals, including both sexes of $H$. "naevius". These specimens represent 37 local samples, including Group A [nine from Kyushu (Kyushu-A) and nine from Chugoku] and Group B [seven from Chubu-Kinki, four from Shikoku, and eight from Kyushu (KyushuB)] as defined previously (Tominaga et al., 2005a,b; Table 2).

Following Tominaga et al. (2005b), we measured 18 morphometric characters [SVL, HL (head length), IND (internarial distance), IOD (interorbital distance), UEW (upper eyelid width), UEL (upper eyelid length), AGD (axilla-groin distance), TRL (trunk length), BTAW (basal tail width), MXTAH (maximum tail height), FLL 
Table 1. Mesurements (in $\mathrm{mm}$ ) of 18 morphometric characters and numbers of two meristic chrarcters in type specimens of Hynobius naevius. Asterisks indicate specimens used in presenet study. RMNH2306A corresponds to lectotype. For abbreviations, refer to text.

\begin{tabular}{|c|c|c|c|c|c|c|c|c|c|c|}
\hline Specimen Number & SVL & $\mathrm{HL}$ & IND & IOD & UEW & UEL & AGD & TRL & BTAW & MXTAH \\
\hline$\overline{\mathrm{RMNH} 2306 \mathrm{~A}^{*}}$ & 82.2 & 18.9 & 4.4 & 4.3 & 2.4 & 4.1 & 45.4 & 63.3 & 6.6 & 7.5 \\
\hline RMNH2306B & 64.0 & 16.3 & 3.8 & 3.5 & 2.2 & 3.7 & 32.8 & 47.7 & 5.7 & 5.7 \\
\hline RMNH2306C* & 74.0 & 17.0 & 4.2 & 3.4 & 2.1 & 4.0 & 39.0 & 57.0 & 7.2 & 7.6 \\
\hline RMNH2306D & 65.8 & 15.3 & 3.4 & 3.1 & 2.2 & 3.6 & 34.4 & 50.5 & 6.0 & 7.2 \\
\hline RMNH2306-1 & 85.0 & 18.3 & 4.5 & 4.2 & 2.5 & 4.3 & 47.7 & 66.7 & 8.8 & 10.2 \\
\hline RMNH2306-2 & 80.9 & 18.7 & 4.7 & 4.2 & 2.3 & 4.4 & 42.5 & 62.2 & 8.3 & 8.3 \\
\hline RMNH2306-3* & 72.3 & 17.1 & 4.1 & 3.8 & 2.4 & 3.8 & 36.3 & 55.2 & 8.5 & 8.8 \\
\hline RMNH2306-4* & 82.0 & 19.3 & 4.1 & 4.3 & 2.7 & 4.5 & 48.4 & 62.7 & 6.5 & 6.6 \\
\hline RMNH2306-5 & 55.8 & 13.5 & 3.4 & 3.2 & 1.7 & 3.4 & 28.6 & 42.3 & 5.3 & 5.2 \\
\hline RMNH2306-6 & 50.3 & 12.7 & 3.2 & 2.9 & 1.7 & 3.1 & 25.7 & 37.6 & 4.6 & 5.0 \\
\hline RMNH2306-7 & 46.3 & 11.1 & 2.3 & 2.7 & 1.5 & 2.8 & 23.5 & 35.2 & 4.7 & 4.8 \\
\hline $\mathrm{BMA}^{*}$ & 79.0 & 17.5 & 4.3 & 4.4 & 2.6 & 4.4 & 38.5 & 61.5 & 7.1 & 6.2 \\
\hline $\mathrm{BMB}^{*}$ & 77.9 & 17.4 & 4.7 & 4.1 & 2.7 & 4.3 & 40.3 & 60.5 & 6.9 & 8.0 \\
\hline $\mathrm{BMC}^{*}$ & 81.0 & 18.8 & 4.6 & 4.3 & 2.6 & 4.7 & 41.7 & 62.2 & 6.6 & 6.3 \\
\hline Specimen Number & FLL & HLL & $2 \mathrm{FL}$ & $3 F L$ & $3 T L$ & $5 T L$ & VTW & VTL & UJTN & VTN \\
\hline$\overline{\mathrm{RMNH} 2306 \mathrm{~A}^{*}}$ & 18.6 & 22.3 & 3.0 & 3.2 & 4.6 & 1.6 & 4.0 & 3.8 & 73 & 62 \\
\hline RMNH2306B & 16.0 & 18.4 & - & - & - & - & - & - & - & - \\
\hline $\mathrm{RMNH}_{2306 \mathrm{C}^{*}}$ & 17.7 & 21.1 & 3.0 & 2.9 & 4.9 & 2.6 & 3.8 & 3.2 & 76 & 52 \\
\hline RMNH2306D & 15.7 & 18.2 & - & - & - & - & - & - & - & - \\
\hline RMNH2306-1 & 19.3 & 20.0 & - & - & - & - & - & - & - & - \\
\hline RMNH2306-2 & 17.6 & 21.8 & - & - & - & - & - & - & - & - \\
\hline RMNH2306-3* & 17.5 & 20.2 & 2.4 & 2.5 & 5.0 & 1.4 & 3.9 & 3.5 & 83 & 54 \\
\hline RMNH2306-4* & 19.5 & 22.9 & 3.6 & 3.5 & 5.4 & 2.1 & 4.2 & 4.2 & 82 & 60 \\
\hline RMNH2306-5 & 13.2 & 16.2 & - & - & - & - & - & - & - & - \\
\hline RMNH2306-6 & 11.7 & 14.4 & - & - & - & - & - & - & - & - \\
\hline RMNH2306-7 & 10.2 & 14.0 & - & - & - & - & - & - & - & - \\
\hline BMA $^{*}$ & 18.2 & 22.5 & 2.9 & 2.6 & 4.6 & 1.7 & 3.7 & 3.3 & 76 & 51 \\
\hline $\mathrm{BMB}^{*}$ & 19.0 & 22.7 & 2.7 & 3.2 & 5.2 & 2.0 & 4.5 & 3.6 & 75 & 56 \\
\hline $\mathrm{BMC}^{*}$ & 21.3 & 22.7 & 3.5 & 2.9 & 5.7 & 2.1 & 4.7 & 4.6 & 85 & 62 \\
\hline
\end{tabular}

(forelimb length), HLL (hindlimb length), 2FL (second finger length), 3FL (third finger length), 3TL (third toe length), 5TL (fifth toe length), VTW (vomerine tooth series width), and VTL (vomerine tooth series length)] and counted two meristic characters [UJTN (number of upper jaw teeth) and VTN (number of vomerine teeth)]. Although some of these characters vary sexually (Tominaga et al., 2005b), we combined sexes for each sample for comparison with the sample of the type series, which may include both sexes.

We conducted a linear discriminant analysis (DISCRIM; SAS, 1990) for 37 local samples using 18 morphometric characters (data for specimens of the local samples are available on request from the authors), and on the basis of linear discriminant functions thus obtained, we determined the local sample with which each of the seven type specimens was associated.

We also performed a canonical discriminant analysis (CANDISC: SAS, 1990) to detect which of the 37 local samples is most similar to the sample of the type series. Using Mahalanobis distances thus obtained, we employed a multi-dimensional scaling (MDS: Lessa, 1990) analysis to visualize overall similarities between the sample of the type series and local samples. All measurements were logtransformed in these multivariate analyses.

We compared five morphological characters that are known to exhibit definite geographic variation in the two groups of $H$. "naevius" (SVL, VTW/VTL, 5TL/3TL, UJTN, and VTN: Tominaga et al., 2005b) between the sample of the type series and each local sample by multiple comparisons using Dunnett's (Zar, 1984) or Steel's test (Steel, 1959; Zar, 1984). Finally, we compared the gross pattern of body markings between the sample of the type series and each local sample following Tominaga et al. (2005b). Comparison of ground color of the body was impossible because of discoloration of the type series, as shown below.

\section{RESULTS}

The lectotype (RMNH 2306A) of S. naevia (=H. naevius) is shown in Fig. 1. Although collected more than 170 years ago, this specimen has been kept in good condition, showing no remarkable damage during long preservation. While body color has faded seriously, features of the color pattern (no markings on the dorsal surface of the trunk, but with relatively large white markings on the lateral to ventral surfaces of the trunk) are well retained and coincide with the original description (Temminck and Schlegel, 1838). Paralectotypes examined in this study (three stored in RMNH and three in $\mathrm{BM})$ are also in good condition, although coloration has faded as in the lectotype. In all specimens of the type series, internal organs were removed.

Measurements and counts of the type series are shown in Table 1. All of the type specimens have five toes and a fairly thick tail that is gradually narrowed towards the tip. These features, as well as the color pattern, of the type series are well concordant with the original description of $S$. naevia. The specimens are large in body size and have a moderately long vomerine tooth series.

As a result of DISCRIM, five of the seven type specimens were estimated to be associated with Group A from Kyushu (Kyushu-A: Samples 21 and 24-26), and the remaining two with Group A from Chugoku (Samples 14 and 19).

In the result of CANDISC, the eigenvalues of the first (CAN1) and second (CAN2) axes accounted for 13.29 (pro- 
Table 2. Number, locality name, local group, genetic/morphological group, and size of samples used for morphological survey.

\begin{tabular}{|c|c|c|c|c|}
\hline \multirow{2}{*}{$\begin{array}{l}\text { Sample number and } \\
\text { locality name }\end{array}$} & \multirow{2}{*}{$\begin{array}{l}\text { Local } \\
\text { sample } \\
\text { group }\end{array}$} & \multirow{2}{*}{$\begin{array}{l}\text { Genetic/ } \\
\text { morphological } \\
\text { group }\end{array}$} & \multicolumn{2}{|c|}{ Sample size } \\
\hline & & & Male & Female \\
\hline 1 Maze & Chubu & $\mathrm{B}$ & 12 & 8 \\
\hline 2 Fujihashi & Chubu & B & 20 & 15 \\
\hline 3 Tsuchiyama & Kinki & B & 8 & 4 \\
\hline 4 Misugi & Kinki & B & 6 & 6 \\
\hline 5 Izumi & Kinki & B & 7 & 9 \\
\hline 6 Kudoyama & Kinki & B & 11 & - \\
\hline 7 Kozagawa & Kinki & B & 7 & 5 \\
\hline 8 Higashiiyayama & Shikoku & B & 40 & 16 \\
\hline 9 Tosayama & Shikoku & B & 15 & 4 \\
\hline 10 Saijyo & Shikoku & B & 11 & 10 \\
\hline 11 Oda & Shikoku & B & 3 & 6 \\
\hline 12 Katsuta & Chugoku & A & 6 & - \\
\hline 13 Nichinan & Chugoku & $A$ & 14 & - \\
\hline 14 Yuki & Chugoku & A & 9 & - \\
\hline 15 Daito & Chugoku & A & 8 & - \\
\hline 16 Fukutomi & Chugoku & A & 4 & - \\
\hline 17 Geihoku & Chugoku & $A$ & 10 & - \\
\hline 18 Yoshiwa & Chugoku & A & 22 & - \\
\hline 19 Asahi & Chugoku & $A$ & 6 & 3 \\
\hline 20 Toyota & Chugoku & $A$ & 16 & 7 \\
\hline 21 Kitakyushu-A & Kyushu-A & A & 24 & 6 \\
\hline 22 Wakamiya & Kyushu-A & $A$ & 7 & - \\
\hline 23 Amagi-A & Kyushu-A & A & 13 & 8 \\
\hline 24 Fukuoka & Kyushu-A & $A$ & 16 & 8 \\
\hline 25 Sechiwara & Kyushu-A & A & 6 & 4 \\
\hline 26 Tara-dake & Kyushu-A & A & 5 & 7 \\
\hline $27 \mathrm{Aki}$ & Kyushu-A & A & 10 & - \\
\hline 28 Kokonoe & Kyushu-A & A & 18 & 4 \\
\hline 29 Kikuka & Kyushu-A & A & 10 & 4 \\
\hline 30 Kitakyushu-B & Kyushu-B & B & 20 & 14 \\
\hline 31 Amagi-B & Kyushu-B & B & 19 & 17 \\
\hline 32 Ume & Kyushu-B & B & 11 & 10 \\
\hline 33 Yabe & Kyushu-B & $B$ & 21 & 3 \\
\hline 34 Itsuki & Kyushu-B & B & 12 & 4 \\
\hline 35 Miyanojyo & Kyushu-B & $B$ & 10 & 8 \\
\hline 36 Tano & Kyushu-B & B & 13 & 7 \\
\hline 37 Kanoya & Kyushu-B & B & 6 & 4 \\
\hline
\end{tabular}

portion=0.71) and 1.68 (proportion=0.09), respectively, and Groups A and B were almost completely separated by these axes. Five of the seven type specimens were positioned within the range of Kyushu-A, and the remaining two types also were located near the range of Kyushu-A (Fig. 2).

After 13 iterations with a Kruskal stress value of 0.042 and with uncorrected distance correlations of 1.00 , MDS reached convergences. This result indicates that among 37 local samples, Sample 26 belonging to Kyushu-A is most similar to the type series (Fig. 3).

The type series of $H$. naevius was relatively large, with a mean SVL of 78.3 (range=72.3-82.2) mm. Only four samples from Chugoku (Samples 12-15) and eight from Kyushu (Samples 21-24 and 26-29), all belonging to Group A, did not differ significantly from the type series. The remaining samples of the two groups were significantly smaller in SVL than the type series (Dunnett's test, $P<0.05$ ).

The fifth toe of the type specimens is well developed, and median of 5 TL/3TL was $37.0 \%$ (range $=28.0-53.1 \%$ ). In this character, only four samples from Chugoku (Samples 12 and 14-16) and nine from Kyushu (Samples 21-29) of

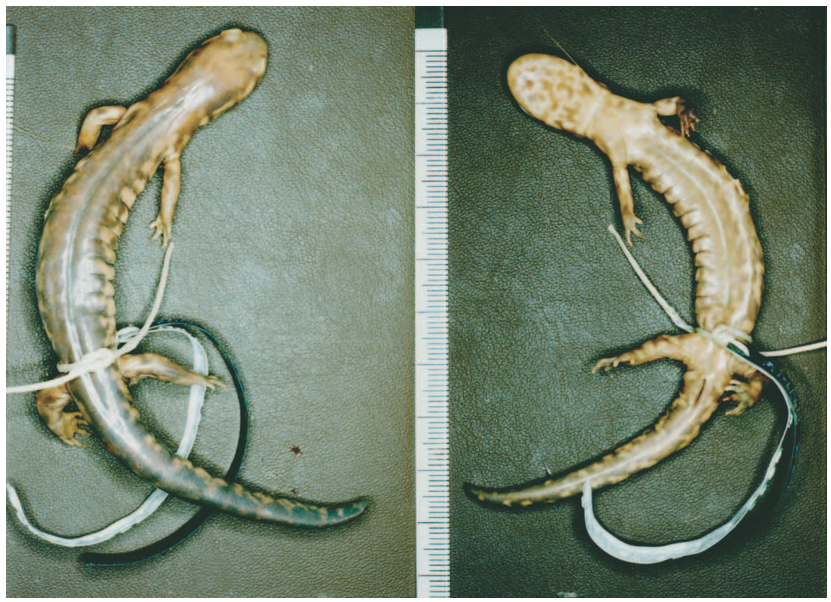

Fig. 1. Dorsal (left) and ventral (right) views of the lectotype of Salamandra naevia (=Hynobius naevius) (RMNH 2306A).

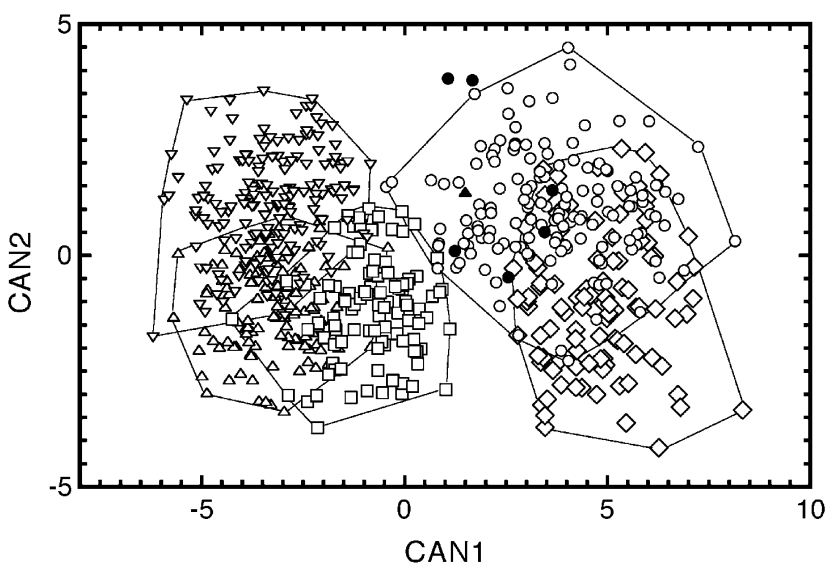

Fig. 2. Plots of first against second canonical axis based on CANDISC for specimens of the type series and 37 local samples of Hynobius naevius. Closed triangle, lectotype; closed circles, paralectotypes ; open circles, Kyushu-A; open diamonds, Chugoku; open squares, Shikoku; open triangles, Chubu-Kinki; open inverted triangles, Kyushu-B.

Group A, and one sample from Shikoku (sample 9) of Group $B$, did not differ significantly from the type series: all remaining samples had significantly smaller 5TL/3TL values than the type series (Steel's test $P<0.05$ ).

The type specimens have a moderately long vomerine tooth series, and the median of VTW/VTL was $111.7 \%$ (range $=100.0-125.0 \%$ ). Only four samples from northwestern Kyushu (Samples 22 and 24-26) of Group A, and one sample from Kinki (Sample 6) and all samples from Shikoku (Samples 8-11) of Group B, did not differ significantly from the type series in this character. The vomerine tooth series in the type series was significantly longer than all samples from Chugoku and five from Kyushu of Group A, but was significantly shorter than all samples of Group B from Kyushu (Kyushu-B; Steel's test, $P<0.05$ ).

The number of vomerine teeth (VTN) of the type specimens is very large, with a median of 56 (range=51-62). In this character, only one sample (Sample 26) of Kyushu-A and five (Samples 30, 32, and 35-37) of Kyushu-B did not 


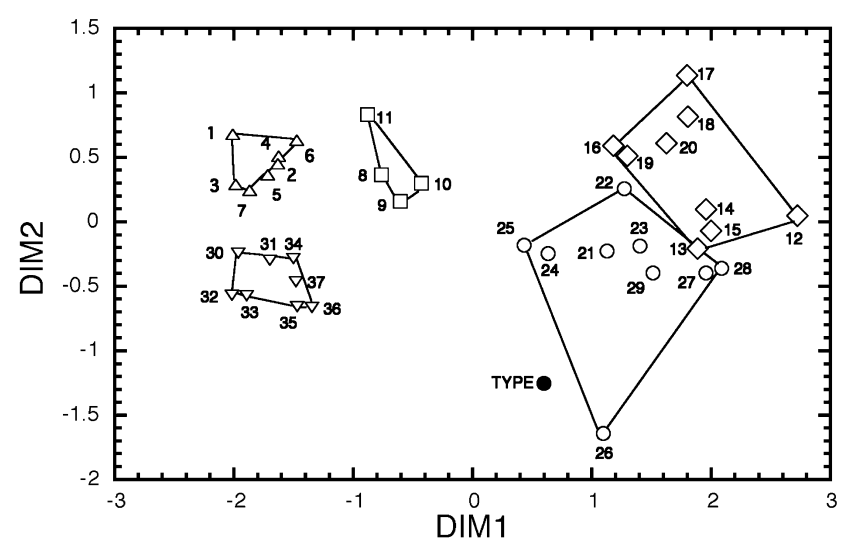

Fig. 3. Relationships among sample of the type series and 37 local samples of Hynobius naevius resolved from MDS using Mahalanobis distance. Closed circle, type series; open circles, Kyushu-A; open diamonds, Chugoku; open squares, Shikoku; open triangles, Chubu-Kinki; open inverted triangles, Kyushu-B. For sample numbers, refer to Table 2 .

differ significantly from the type series: all remaining samples had significantly fewer teeth than the type series (Steel's test, $P<0.05$ ).

The type specimens also have a large number of upper jaw teeth, with the median of UJTN being 76 (range=73-85). Only two samples (Samples 16 and 20) from Chugoku and six samples (Samples 21, 23, and 26-29) from Kyushu of Group A did not differ significantly from the type series in this character; all remaining samples had significantly fewer teeth than the type series (Steel's test, $P<0.05$ ).

From these univariate comparisons, it is obvious that the local sample most similar to the type series is Sample 26 of Group A from northwestern Kyushu, because this sample did not differ significantly from the type series in any of the five variables compared.

Body color of the type series has faded, as mentioned above. Nevertheless, we could confirm that all of the type specimens lack markings on the dorsal surface of the trunk, but possess relatively large white markings on the lateral and ventral surfaces of the trunk. Similar features in body coloration were observed in specimens of Group A from Kyushu, and notably, most specimens of Samples 22-26 had this pattern of markings.

\section{DISCUSSION}

The type locality of $H$. naevius has long been a subject of debate (Stejneger, 1907; Dunn, 1923; Tago, 1931; Okada, 1934, 1935; Sato 1937). Stejneger (1907) surmised that Siebold obtained his specimens from Hondo (Honshu) and Shikoku, but not from Kyushu. Similarly, Dunn (1923) noted the type locality of this species to be "Mountainous parts of Hondo and Shikoku", which refers to a wide geographic range in Japan. However, he also admitted that the type locality of this species was very vaguely given in the original description. Subsequently, Tago (1931) listed the type locality of this species (as Pseudosalamandra naevia) to be the Biruzen (=Hiruzen) region, Maniwa-gun, Mimasaka-no-Kuni of Okayama Prefecture. Both Okada $(1934,1935)$ and Sato (1937) presumably followed Tago
(1931) and referred to Mimasaku (sic), Bizen, Okayama, and the Birzen district, Maniwa-gun Okayama-ken, respectively, as the type locality of $H$. naevius. However, it is unclear on what bases these authors ascertained their type localities. Sato (1943) subsequently referred to the Chugoku samples as the "typical form" of $H$. naeviuis, but did not refer to the type locality of this species.

More recently, Hoogmoed (1978), in designating the lectotype of $H$. naevius, regarded Sagami (present Kanagawa), Shinano (present Nagano), Tanba (present Kyoto), and Tazima (Present Hyogo) in Hondo (present Honshu), and Tosa (present Kochi) in Shikoku, as the type locality of $H$. naevius. These localities correspond to the range of S. unguiculata Temminck and Schlegel, 1838 [=Onychodactylus japonicus (Houttuyn, 1782)] reported by Temminck and Schlegel (1838), who vaguely noted the distributional range of $S$. naevia $(=H$. naevius) to be similar to that of $S$. unguiculata. Although Frost $(1985,2004)$ adopted Hoogmoed's (1978) view, $H$. naevius is actually absent from, at least, Sagami, Shinano, and Tanba (Sato, 1943; Kuramoto, 1979; Matsui, 1981; Matsui and Misawa, 1996). Therefore, we believe that the type locality suggested in the original description and followed by subsequent authors including Hoogmoed (1978) and Frost $(1985,2004)$ is incorrect. In this way, the type locality of $H$. naevius has been far from clear.

In this study, the results of DISCRIM indicated that the lectotype and all the paralectotypes examined could be invariably associated with Group A of Tominaga et al. $(20005 a, b)$, and, moreover, five of them with the samples from northern Kyushu. The results of CANDISC also revealed that samples of Group A from northern Kyushu most resemble the type specimens, and the results of MDS further indicated that Sample 26 from northwestern Kyushu is most similar to the type series. Besides these, the results of univariate analyses using five variables also indicated that Sample 26 is the sample that fits all characteristics of the type specimens of $H$. naevius (very large SVL, well developed fifth toe, moderately long vomerine tooth series, and large numbers of vomerine and upper jaw teeth). The body color pattern of this sample, mottled with large white blotches laterally and ventrally, but not dorsally on the trunk, also coincides with that of the type specimens.

Thus, from characteristics of external morphology, Group $A$ is more similar to the type series of $H$. naevius than is Group $\mathrm{B}$, and, more specifically, specimens of Sample 26 from Mt. Tara-dake, a mountain on the border of Saga and Nagasaki Prefectures, northwestern Kyushu, is most similar to the type specimens among the Group A specimens. Although the results of DISCRIM indicated two of the type specimens to be associated with Chugoku samples of Group A, this grouping seems incorrect, because these two type specimens lack dorsal markings, like Kyushu-A and unlike the Chugoku samples. We suspect this result to have derived from some factors related to sex and/or preservational condition of the specimens used, and not from the presence of specimens from more than one locality in the type series of $H$ naevius.

From these results, we conclude that Group A of Tominaga et al. (2005a,b) corresponds to true $H$. naevius. In addition, the type locality of $H$. naevius is supposed to be somewhere in the mountains ranging from Saga to Nagasaki Prefectures of Kyushu. Philipp Franz von Siebold, 
who collected this species and took specimens to Europe, stayed in Nagasaki while visiting Japan. The locality of the type specimens, which he also took to Europe, (=type locality) of another hynobiid, S. nebulosa Temminck and Schlegel, $1838(=H$. nebulosus) is clearly recorded as "monts Mits jama (les trois monts) situés dans les environs de Nagasaki" (Mt. Mitsuyama located near Nagasaki). Siebold himself probably collected some $H$. nebulosus specimens in that locality. Siebold also noted collection localities of Triton japonicus Temminck, 1836 (=Andrias japonicus) and $S$. unguiculata (=O. japonicus). Siebold obtained these species during his travels between Nagasaki and Edo (present Tokyo), and they were probably impressive enough for him to record the localities of collection.

Unlike these species, some Japanese amphibians, including $H$. naevius that Siebold sent to Europe for description, have no exact locality data. These species were probably not rare around Nagasaki, but were not collected by Siebold himself and impressed him little. Probably they were collected from suburbs or adjacent localities of the city of Nagasaki by someone and presented to Siebold. This idea is well concordant with the type locality of $H$. naevius estimated in this study.

From a study using the mitochondrial $12 \mathrm{~S}$ and $16 \mathrm{~S}$ rRNA genes, Tominaga et al. (2006) detected two distinct genetic lineages (Clades 1 and 2) in Group $A$, in which Sample 26 and neighboring samples of Clade 1 from northwestern Kyushu are clearly split from Clade 2 consisting of samples from northeastern Kyushu and Chugoku. Future DNA analyses of long-preserved type specimens (cf. Stuart et al., 2006) could specify the type locality with more validity. In any case, the results of the present study force us to conclude that Group B of Tominaga et al. (2005a, b) should no longer be called $H$. naevius.

\section{ACKNOWLEDGMENTS}

We are grateful to M. S. Hoogmoed (RMNH) and C. McCarthy and B. T. Clarke (BM) for allowing the junior author to examine type specimens under their care. We thank K. Nishikawa, S. Sato, and $\mathrm{S}$. Tanabe for valuable advice throughout our study. We are also much indebted to H. Ashida, T. Hayashi, S. Ikeda, S. Ichihara, M. Kato, K. Kawano, S. Matsuzuki, K. Matsuo, Y. Misawa, K. Nishikawa, S. Okada, S. Sato, T. Shimada, Z. Shimizu, T. Sota, T. Sugahara, T. Sugihara, S. Tanabe, Y. Tatewaki, T. Utsunomiya, Y. Utsunomiya, M. Yamagami, E. Yamamoto, N. Yamanaka, and $Y$ Yasukawa for help in collecting specimens, and to K. Hatooka, S. Okada, M. Sakamoto, S. Sato, and S. Tanabe for allowing us to examine specimens in their care. We also thank $\mathrm{H}$. Ota and two anonymous reviewers for valuable comments on our manuscript. The senior author thanks T. Mori, H. lida, and H. Minei for their continuous encouragement. This study was supported by grants under The Monbusho International Scientific Research Program (Field Research, No. 10041166) to the junior author.

\section{REFERENCES}

Dunn ER (1923) The salamanders of the family Hynobiidae. Proc Amer Acad Arts Sci 58: 445-523

Frost DR (Ed) (1985) Amphibian Species of the World: A Taxonomic and Geographic Reference. Allen Press Inc. and the Association of Systematics Collections, Lawrence

Frost DR (2004) Amphibian species of the world: an online reference, Version 3.0 (22 August, 2004). American Museum of Natural History, New York, Electronic database accessible at http://research.amnh.org/herpetology/amphibia/index.html
Hoogmoed MS (1978) An annotated review of the salamander types described in the Fauna Japonica. Zool Medede 53: 91-105

Kuramoto M (1979) Hynobius naevius naevius. In "Final Report of Reptiles and Aamphibians Survey of the Second National Survey on the Natural Environment in Japan, 1978" Japan Environmental Agency, Tokyo, pp 86-89

Lessa E (1990) Multidimensional analysis of geographic genetic structure. Syst Zool 39: 242-252

Matsui M (1981) Hynobius naevius naevius (Schlegel). In "Final Report of Reptiles and Amphibians Survey of the Second National Survey on the Natural Environment in Japan, $1978 \mathrm{Pt}$. 2" Nature Conservation Society of Japan, Tokyo, pp 143-150

Matsui M, Misawa Y (1996) Hynobius naevius. In "The Encyclopedia of Animals in Japan 5, Amphibians, Reptiles, Chondrichthyes" Ed by S Sengoku, T Hikida, M Matsui, K Nakaya, Heibonsha, Tokyo, p 23

Okada $Y$ (1934) A contribution toward a check list of the urodeles of Japan. Copeia 1934: 16-19

Okada Y (1935) A general review of the classification and distribution of Japanese salamanders. Zool Mag Tokyo 47: 575-589

Oyama J (1940) Exhibision of wax models of Hynobius from Kyushu, showing body color in life. Acta Anat Nippon 16: 34-35

Oyama J (1947) Hynobius naevius yatsui. Zool Mag Tokyo 57: 106107

Sakamoto M, Nishikawa K, Matsui M (2005) Two types of Hynobius naevius from the central region of Kyushu Island, Japan (Caudata: Hynobiidae). Cur Herpetol 24: 67-77

SAS (1990) SAS/STAT User's Guide. SAS Institute Inc., Cary, North Carolina

Sato I (1937) A synopsis of the family Hynobiidae of Japan. Bull Biogeogr Soc Jpn 7: 31-45

Sato I (1943) A Monograph of the Tailed Batrachians of Japan. Nippon Shuppansha, Osaka

Steel RGD (1959) A multiple comparison rank sum test: treatment versus control. Biometrics 15: 560-572

Stejneger $L$ (1907) Herpetology of Japan and adjacent territory. Bull US Nat Mus 58: 1-577

Stuart BL, Inger RF, Voris HK (2006) High levels of cryptic species diversity revealed by sympatric lineages of Southeast Asian forest frogs. Biol Lett published online at http://dx.doi.org/10.1098/ rsbl.2006.0505

Tago K (1931) Newts and Salamanders. Geisoudo, Kyoto

Temminck CJ, Schlegel H (1838) Les Sauriens. Les Batraciens. In "Fauna Japonica" Ed by PF de Siebold, Lugdunni Batavorum, Amsterdam, pp 97-144+pl VI

Tominaga A, Matsui M, Nishikawa K, Sato S (2003) Occurrence of two types of Hynobius naevius in northern Kyushu, Japan (Amphibia: Urodela). Zool Sci 20: 1467-1476

Tominaga A, Matsui M, Nishikawa K, Tanabe S, Sato S (2005a) Genetic differentiations of Hynobius naevius (Amphibia: Hynobiidae) as revealed by allozyme analysis. Biochem Syst Ecol 33: 921-937

Tominaga A, Matsui M, Nishikawa K, Tanabe S, Sato S (2005b) Morphological discrimination of two genetic groups of Japanese salamander, Hynobius naevius (Amphibia, Caudata). Zool Sci 22: $1229-1244$

Tominaga A, Matsui M, Nishikawa K, Tanabe S (2006) Phylogenetic relationships of Hynobius naevius (Amphibia: Caudata) as revealed by mitochondrial $12 \mathrm{~S}$ and $16 \mathrm{~S}$ rRNA genes. Mol Phylogenet Evol 38: 677-684

Zar JH (1984) Biostatistical Analysis. 2nd ed, Prentice-Hall, Englewood Cliffs

(Received December 29, 2006 / Accepted May 7, 2007) 